\title{
The Development of a Qualitative Ranking Tool for the Preliminary Selection of Abandoned Asbestos Mine Sites for Rehabilitation
}

\author{
Herman Cornelissen \\ Mintek \\ 200 Malibongwe Drive, Randburg, South Africa \\ hermanc@mintek.co.za
}

\begin{abstract}
This paper presents the development of a matrix that considers health and safety, environmental and land utility risks in the problem of prioritising asbestos mine sites for rehabilitation with limited information at desktop level from a population of such sites. Qualitative risk analysis techniques were developed along with expert input and applied to publicly available and/or remotely sensed information to calculate a relative risk rank and thus to aid the prioritisation of abandoned asbestos mine sites at desktop level for further investigation. The paper outlines the process followed and the results obtained and concludes that the application of risk analysis techniques can be a valuable tool to determine a relative priority of abandoned mine sites with limited information in order to rank them for further investigation.
\end{abstract}

Keywords: Risk ranking, asbestos, mine rehabilitation

\section{Introduction}

South Africa has a long history of mining and a current legacy of many thousands of abandoned mines in all areas of the country. One of the commodities that has been mined extensively in the past but that has been proven to cause significant adverse health effects, is asbestos. The national database of abandoned mines, maintained by the Council for Geoscience of South Africa, indicates that there are 249 known abandoned asbestos mines in South Africa.

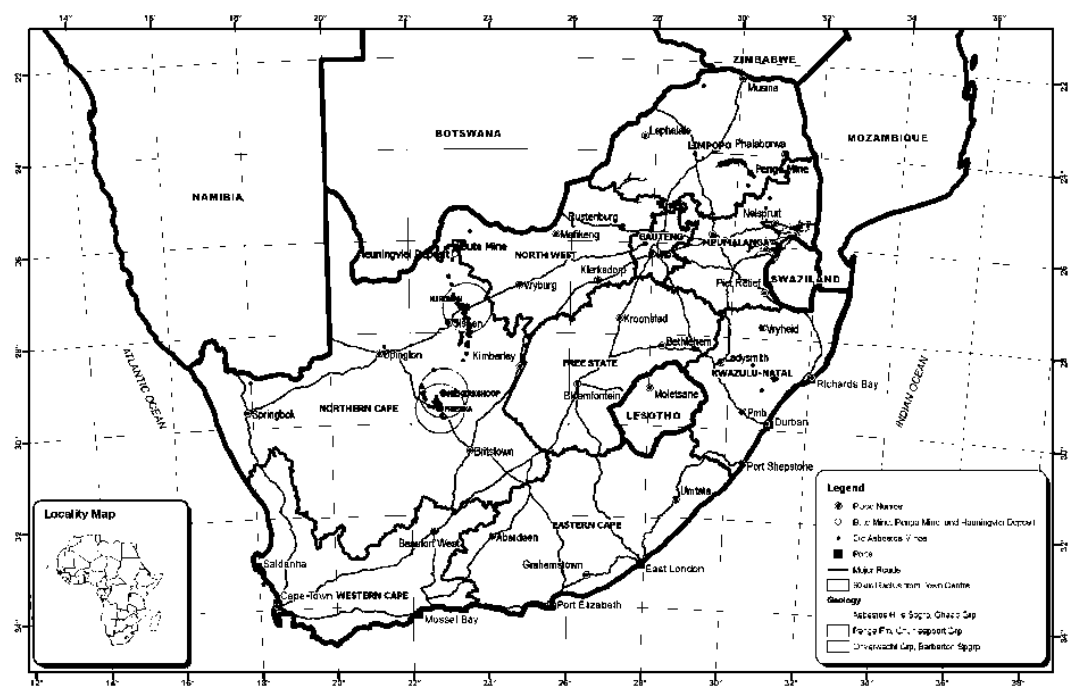

Fig. 1: Location of major asbestos mining areas in South Africa (Source: Mintek).

The national Department of Mineral Resources of South Africa, (DMR) includes the rehabilitation of some of these mines in their annual plans and provides a budget for the rehabilitation work. The task of investigating, selecting and recommending sites for rehabilitation from the total population of asbestos mines is contracted to Mintek, a state-owned enterprise reporting to the DMR. This paper describes the site ranking method that was developed by Mintek to assist in 
the preliminary selection of sites from the total population as a first step in identifying sites for further investigation and eventual rehabilitation.

\section{Problem description}

The problem was to find a repeatable, practical and defensible manner in which to determine, amongst the population of asbestos mines known from the database, which would be the optimal choices to target for next-level investigations. The objective was to confine the possible selection of potential project sites using desktop tools to deliver results quickly and cost effectively. Important additional considerations were both the communication of the method and results to decision makers and the continued future replication of the technique for the initial mine rehabilitation prioritisation stage.

\section{Scope}

The scope of the method that had to be devised was bound by parameters of practicality and cost. A methodology that would be recognizable to practitioners of risk analysis yet work with limited information and yield results that could be presented intuitively to decision makers was the ideal. The use of public access data to inform decisions about the sites was a key consideration. The problem of information availability in this instance is reflected by Al-Rashadan, et al (1999). In this respect, the expert input assisted greatly to bring the practical experience of decades of field observations to the individual metrics of the risk analysis. The method devised serves only to inform the site selection process and is not an exhaustive site risk assessment, which is done at the stage of site investigation, when actual site-level data can be obtained. While the tools developed from risk assessment practice were useful for the application scope, it was not necessary for this method to proceed to risk quantification in absolute terms. The established risk assessment processes of establish-identifyanalyse-evaluate-manage were thus significantly redacted to a two-step process that serves the stated objective and data limitations. As Aven (2016) has noted, 'the suitability of the metrics depend on the situation', sentiments echoed by Zhang, et al (2010) in their investigation of correlation between environmental and risk assessments, wherein the authors noted the need for the assessment paradigm to consider the objective and the availability of information. The focus of the method was to understand the environmental and human context to identify the hazards to the potentially exposed population.

\section{Methodology}

The method was conceptualised from the realisation that various asbestos mines that will be rehabilitated, differ in terms of size, complexity and relative hazard to communities. The manifestation of the hazards from abandoned asbestos mines relate to a high degree to the proximity of these sites to human settlements, many of which are located in rural areas of South Africa. The observed interaction of communities with the abandoned asbestos mines in rural areas, whether the mines were previously rehabilitated or not, was an important additional consideration. The ranking model therefore includes metrics of Release assessment, Exposure assessment and Consequence assessment (per Covello and Merkhofer, 1993). The model uses these risk metrics in three categories, namely:

- Health and Safety (the potential impact of the site conditions on humans),

- Environmental (the potential impact of the site on the surrounding natural environment) and

- Land utility (including evidence of illegal mine access, the site's potential to hamper future development by sterilising land, etc.) in the risk analysis and eventual ranking of each site.

\subsection{Health and Safety}

The health and safety metric constitutes the most significant consideration in determining the total site risk rank. Asbestos is known to be carcinogenic and, to this end, its proximity to human settlements would form a significant part of the desktop measurement of its relative risk. This metric thus included elements of release assessment, exposure assessment and consequence assessment. The probability intervals of this metric follow those named by Karkoszka (2015) Van der Walt, in his PhD thesis of 1992 entitled: "A spatial model for the determination of the pollution potential of asbestos dumps" (translated from the original title language), did extensive work to prove that various types of asbestos disperse differently and has proven that the type of asbestos and regional setting, both fundamentally affect the dispersion characteristics of the various types of asbestos found in South Africa. For the purposes of the model, the type of asbestos was not considered. The health and safety metric combines a qualitative assessment of probability with a quantitative magnitude metric. The metric specifically considers the proximity of the abandoned mine site to human settlements, being 
a proxy for potential human interaction. For the purposes of the model in this stage, a directly linear asbestos fibre dispersion in all wind directions from the source was assumed. More specific asbestos fibre dispersion modelling is a potential future improvement, as the data is readily available for all types of asbestos historically mined in South Africa.

\subsection{Environmental Impact}

Besides health and safety impacts, abandoned asbestos mines also have impacts on the natural environment. This metric included a qualitative assessment of potential for uncontrolled erosion of asbestos fibres into rivers and water courses, proximity to protected natural environments and several other aspects. In order to derive information from public sources, this metric called for observations from public access satellite imagery of each site as well as searches of historical records and published topographical maps to determine the age of the mine and visible erosion features (if any) as well as erosion potential, derived from geology maps and site topography. These were developed along with the metric of the potential impact of any environmental degradation on the surrounding landscape.

\subsection{Land utility}

Land utility is the final major metric that aims to provide at least qualitative assessment of the potential for the abandoned mine site to impact negatively on current or future land uses or hamper economic development in the area. One aspect of this metric that proved problematic to determine from public-source remote data, is the consideration of potential access into old mine workings. This aspect of the land utility metric can only be determined with certainty at site investigation stage. Observer experience in satellite photo and land use interpretation plays a key role in the assessment of the impact on land utility in this metric. The input of expert knowledge, along with comparative mine history, geological setting and size of the operation played a key role in defining the metrics and probability of encountering certain mine features. Experience as shown that communities often interact with asbestos mine sites for the purposes of firewood harvesting or grazing of livestock. (Figure 2)

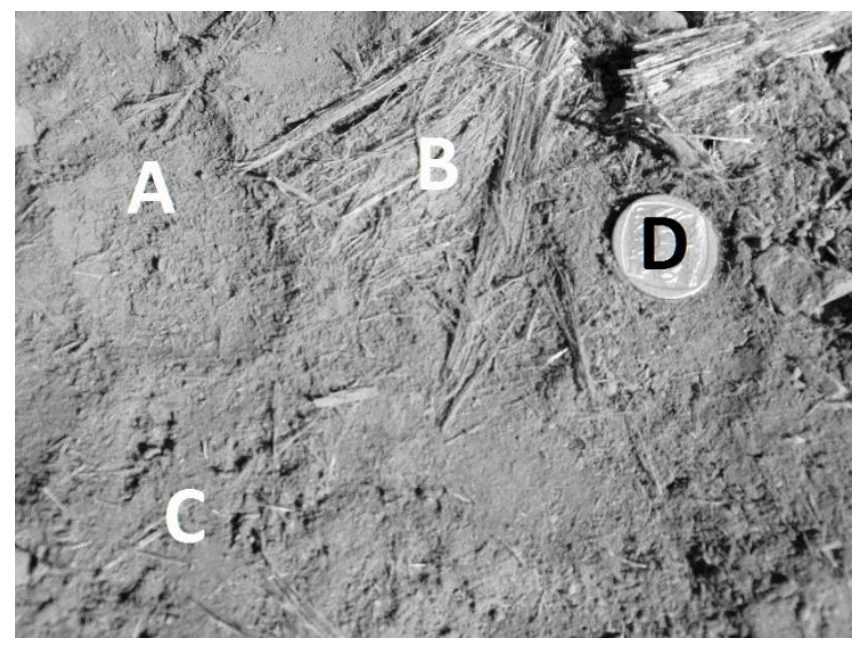

Fig. 2: Image taken on an abandoned asbestos mine in the Limpopo province, South Africa. The image displays a human footprint (A) and animal footprints (C) amongst trampled and fraying amosite fibres (B). A South African R5 coin is included for scale (D) (Source: Author).

The utilisation of abandoned mine land is more prevalent the closer the mine is to the community, so proximity of the community to the mine, easily measurable with desktop remote data, emerged as a common denominator for overall site risk in almost all metrics. The sum of the three major metrics constitute the total site risk rank in the model. The results from these metrics used different scales, with the result that a weighting system is internally contained, as the Health and Safety metric accounts for $41.7 \%$ of the total risk rank, Environmental metric for $33.3 \%$ and Land utility for $25 \%$.

\subsection{Cost and complexity}

While the three major metrics allowed for the analysis and comparison of various mine sites to each other, the model still required a consideration of cost and complexity. This was necessary to effectively communicate project prioritisation 
to decision-makers, who control project funding. The cost and complexity metric that was developed used information derived from the actual cost of completed rehabilitation projects. This metric allows similarly risky mines to be compared in terms of cost and the relative difficulty of accessing the site for rehabilitation. (a function of project size, project complexity, project location, project topography, locations relative to supply centres and the cost of similar past projects) Some sites are in extremely remote areas or required special measures to rehabilitate, requiring complex equipment access or other considerations.

\section{Results}

The results of the application of this methodology was the ability to devise a set of metrics for an initial risk analysis that can be replicated and refined through further field work. This enabled a repeatable process to produce values of comparative risk amongst several project sites through low-cost means. The ranking of the sites by considering their health and safety, environmental and land utility metrics, in addition to the further consideration of their relative cost and complexity, allows for the presentation of the results in a simple matrix that is very easily communicated and understood by policy makers and government executives. The results of the risk ranking, plotted on the Y-axis of a graph, with the Xaxis representing the cost and complexity, allows for the visual presentation of the results of the data in four quadrants reflecting the relative risk, size and complexity and probable project cost of each project. This mode of visualisation is simple to present and elicits intuitive responses from an audience of widely differing level of competence.

\section{Discussion and the importance of the work}

The exercise used the most fundamental tools of risk analysis and enabled a preliminary comparative ranking of several project sites from public information. The accessibility and basic nature of the method allows for future adaptability and repetition of the results. The model remains very simple and there is vast room for improvement. The scope and intent of the model is not, however, to develop a full environmental risk assessment, as the data required is not available at the point in the overall process of site selection when this tool is used.

\section{Conclusion}

This paper describes the process followed using basic risk analysis techniques which have been adapted to the purpose of ranking asbestos mine sites for further investigations and eventual rehabilitation. The risk ranking model that was developed allowed the use of desktop tools along with expert input to rank the sites for further investigation. As a costeffective method that can be simply implemented at desktop level with public information only, this method serves the intended purpose and may be refined for future use. The risk ranking contained in the model did not need to contain an exhaustive risk assessment process in order to produce useable results. The model can be refined further, specifically by incorporating more data relating to asbestos dispersion modelling to refine the hazard metric. The continued updates of cost data from completed project works to determine the major factors that drive rehabilitation cost will serve to refine the cost and complexity metric of the model. The model developed is far removed from an exhaustive risk assessment in many respects but satisfied the scope and intended application objectives.

\section{Acknowledgements}

I acknowledge the guidance of Mr Peter Craven, former General Manager of Business Development for Mintek, in the development of the model. I also acknowledge with gratitude the proofreading of the text by the current General Manager of Business Development, Dr David Powell.

\section{References}

[1] D. Al Rashadan, B. AL-Kloub, A. Dean, T. Al-Shemmeri, "Environmental impact assessment and ranking the environmental projects in Jordan," European Journal of Operational Research., vol. 118, pp. 30-45, 1999.

[2] I. J. van der Walt, "n Ruimtelike model vir die bepaling van die besoedelingspotensiaal van asbes uitskothope," Ph.D. dissertation, Department of Geography and Environmental studies, Potchefstroom University for Christian Higher Education, 1992.

[3] K. Zhang, Y. Peib, C. Linb, "An investigation of correlations between different environmental assessments and risk assessment," International Society for Environmental Information Sciences 2010 Annual Conference (ISEIS). 
[4] Society for Risk Analysis, Committee on Foundations of risk analysis, "SRA Glossary," 2015, [Online]. Available: http://www.sra.org/sites/default/files/pdf/SRA-glossary-approved22june2015-x.pdf

[5] T. Aven, "Risk assessment and risk management: Review of recent advances on their foundation," European Journal Operational Research., vol. 253, pp. 1-13, 2016.

[6] T. Karkoszka, "Evaluation of the processes with application of the environmental risk assessment," Proceedings of the Manufacturing Engineering Society International Conference (MESIC), 2015.

[7] V. T. Covello, M. W. Merkhofer, "Risk assessment methods: Approaches for assessing health and environmental risks,” New York. Plenum Press, 1993. 